\title{
北斗“一带一路”服务性能增强技术研究
}

\author{
周建华 $^{1}$, 陈俊平 $^{2}$, 张晶宇 ${ }^{3}$ \\ （1. 中国人民解放军 32020 部队，武汉 430071；2. 中国科学院上海天文台，上海 200030；
}

3. 中国人民解放军 61081 部队，北京 100094）

\begin{abstract}
摘要：本文结合卫星导航应用及产业发展的整体趋势，对北斗卫星导航系统（以下简称 “北斗”) 的服务性能、应用现状进 行了总体评估和分析。针对北斗应用 “走出去” ，分别从系统服务、特色服务、应用产业三个层面上分析了 “一带一路” 沿 线北斗应用推广存在的主要难题，论证说明提升北斗差异化的竞争力是破解北斗 “走出去” 的重要途径。基于以上分析，针 对北斗星基增强和短报文服务，设计两种特色服务在 “一带一路” 沿线推广应用的初步技术途径和方案。通过在 “一带一路” 沿线国家设置十多个海外监测站，可满足 “一带一路” 国家和地区高精度位置服务的绝大部分需求; 通过研制建设北斗短报 文海外服务系统，可为海量的 “一带一路” 沿线用户提供性能更优、体验更好的短报文通信服务; 针对性给出了北斗特色服 务的示范应用推广构想。最后，从政策层面提出了加快推进北斗在“一带一路”沿线国家应用的保障建议。
\end{abstract}

关键词: 卫星导航; 北斗; “一带一路”; 应用推广; 示范应用

中图分类号：P228 文献标识码：A

\section{Service Performance Enhancement Technologies for BeiDou Navigation Satellite System along the Belt and Road}

\author{
Zhou Jianhua ${ }^{1}$, Chen Junping ${ }^{2}$, Zhang Jingyu ${ }^{3}$ \\ (1. People's Liberation Army 32020 Unit, Wuhan 430071, China; 2. Shanghai Astronomical Observatory, Chinese Academy of \\ Sciences, Shanghai 200030, China; 3. People's Liberation Army 61081 Unit, Beijing 100094, China)
}

\begin{abstract}
To solve problems in globalization of the BeiDou Navigation Satellite System (BDS), this paper first analyzes the service performance and application status of the BDS, based on the overall application and development trend of satellite navigation worldwide. Major problems in the application and promotion of the BDS are analyzed from three aspects, including system service, characteristic service, and application industries; and promoting differentiated competitive powers is proved to be effective in assisting the BDS to "go global". Based on the above analyses, preliminary technical approaches and schemes are designed to promote and apply the satellite-based augmentation and short-message services, two characteristic services of the BDS, along the Belt and Road. By establishing over a dozen of monitoring stations in countries along the Belt and Road, demands of most of these countries for precise positioning can be satisfied. By developing an oversea short-message service system, a short-message communication service, with better performance and experience, can be provided for massive BDS users along the Belt and Road. Promotion ideas for the BDS characteristic services and their demonstration application are also presented. Additionally, some policy suggestions are proposed to accelerate
\end{abstract}

收稿日期 : 2019-06-17; 修回日期 : 2019-07-01

通讯作者: 周建华, 中国人民解放军 32020 部队研究员、副总工程师, 主要研究方向为卫星导航定位技术; E-mail: zjy8712@126.com 资助项目：中国工程院咨询项目 “工程科技支撑 “一带一路” 建设战略研究” (2017-ZD-15)

本刊网址：www.engineering.org.cn/ch/journal/sscae 
the application of the BDS services in countries along the Belt and Road.

Keywords: satellite navigation; BeiDou Navigation Satellite System (BDS); the Belt and Road; application and promotion; demonstration application

\section{一、前言}

北斗卫星导航系统（以下简称 “北斗”）是我国 重要的时空基础设施, 经过 30 多年的发展, 已成为 服务经济社会发展和国防建设的重要力量。随着北 斗三号卫星导航系统的逐步建成, 我国卫星导航领 域的发展重点开始从系统建设逐渐转移到应用推广。

当前, 随着卫星导航技术与相关产业的快速发 展, 全球卫星导航应用逐渐呈现出以下三大趋势。

一是高精度应用逐渐成为主流。2020 年全球四 大卫星导航系统将全部开通运行, 最终将形成多星 座、多频率共存的局面。卫星导航兼容互操作技术 发展使得多系统应用进一步简化，这为终端产业多 样化的发展奠定了坚实基础。随着芯片技术的发展 和低成本器件的性能不断提升, 卫星导航终端应用 逐渐向低成本和高精度应用方向发展, 在无人驾驶、 物联网、智能可穿戴等新兴领域发展的驱动下, 高 精度服务正在成为应用市场的主流 [1]。

二是导航定位授时服务（PNT）走向泛在化、 协同化、智能化。技术的快速进步使人类逐渐实现 了从宏观尺度的深空深海到微观尺度的生物体内部 空间探索, 时空服务需求变得无处不有、无所不在, 泛在化趋势愈加明显。从为用户提供更好的 PNT 服务体验的角度出发, 各类 PNT 器件和技术的发 展及日益成熟, 使得以卫星导航为核心的各类 PNT 服务更趋协同化、智能化 $[2,3]$ 。

三是 “PNT+” 将成为新兴应用与研究领域。
随着天基信息系统服务日益增多，为获取更好的系 统服务, 卫星导航、通信、遥感等天基服务系统融 合一体化的趋势不可避免，基于低轨卫星的导航、 遥感融合应用已进入卫星试验阶段 [4]。低轨卫星 导航、水下导航、室内导航、地基增强等技术逐渐 融入卫星导航 PNT 服务, 逐步形成以卫星导航为 核心的新一代天地一体、无缝覆盖的时空服务体系。 未来, 结合云计算、物联网、人工智能等新兴领域, 将涌现出众多 “PNT + ” 式的新兴技术和应用领域。

\section{二、北斗在 “一带一路” 沿线应用的性能、 现状与困难}

\section{（一）北斗服务性能评估}

与国际上其他卫星导航系统相比，北斗在提供 基本导航服务的同时，还能提供分米级星基增强和 短报文服务。自 2017 年北斗分米级星基增强服务 开通后, 有效提升了北斗系统基本服务的性能, 增 加了卫星导航系统的服务模式。2016-2018 年, 北 斗与全球定位系统（GPS）的双频定位服务性能对 比如图 1 所示。

从图 1 可见, 2017 年开通分米级星基增强服务 后，北斗系统基本服务的精度有较大提升，与 GPS 基本服务的精度相当。开通的北斗分米级星基增强 服务精度显著优于 GPS 的基本服务精度, 而 GPS 自身不具备星基增强功能, 需依托广域扩充系统 （WAAS）实现类似功能。

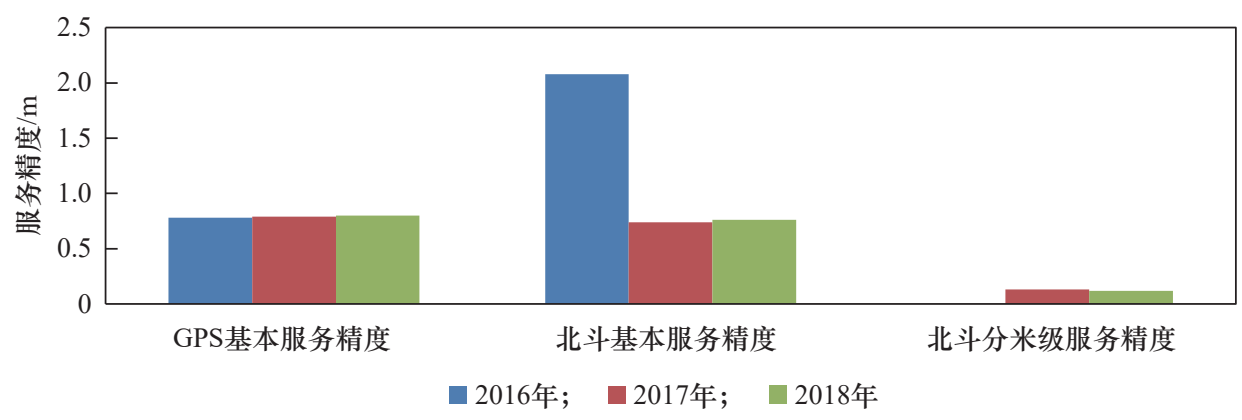

图 1 GPS 与北斗的基本服务、北斗分米级星基增强的服务精度比较 


\section{（二）北斗在 “一带一路” 沿线的应用现状}

经过多年应用推广，北斗 “走出去” 取得了初 步成果，基于北斗基本服务的产业力量先于北斗特 色服务率先在 “一带一路” 沿线形成 “星星之火” 态势。

在国际合作方面，我国先后与老挝、巴基斯坦、 泰国、新加坡、柬埔寨等十几个国家签定合作框架 协议, 开展北斗应用的落地建设。与俄罗斯建立卫 星导航重大事项交流机制; 与阿拉伯国家建立合作 框架，定期召开中阿北斗合作论坛，并于 2018 年 4 月设立北斗首个海外中心一中阿北斗中心; 2018 年 11 月承办联合国全球卫星导航系统国际委 员会第十三届大会，习近平主席向大会致贺信，充 分彰显北斗走向世界的影响力。

在产业服务方面, 目前, 北斗应用已先后进入 “一带一路” 沿线 30 多个国家和地区，实现民企产 品在十余个国家的销售和应用。我国部分企业, 如 上海华测导航技术股份有限公司、上海司南卫星导 航技术股份有限公司、北京合众思壮科技股份有限 公司等，结合 “一带一路” 沿线国家的合作伙伴和 资源，应用北斗／卫星导航捆绑式销售，在行业性 应用服务中取得一些可喜的成绩。

\section{（三）北斗 “一带一路” 应用存在的主要困难}

\section{1. 系统服务层面}

国际卫星导航监测评估系统 2018 年 12 月的结 果 (见图 2) 显示 [5], 在全球范围内, 通过比较单 频定位精度可知, 北斗与美国 GPS 在全球（含 “一 带一路” 国家和地区）的基本服务性能相当; 欧
洲全球导航卫星系统 (Galileo) 由于星座尚不完整, 虽然整体服务性能与北斗和 GPS 相当，但在服务 可用性和连续性方面有待进一步提升; 俄罗斯的 全球卫星导航系统（GLONASS）的服务性能相对 较差。

虽然北斗目前与 GPS 的服务性能相当, 但由 于 GPS 占据先发优势, 全球性的产业力量体系发 展十分成熟，当前已占据卫星导航领域绝大部分市 场，在基本服务市场北斗很难取代 GPS。

\section{2. 特色服务层面}

除基本服务外, 北斗最大的特色在于具有提供 分米级星基增强和短报文等特色服务的能力。

2017 年北斗建成的分米级星基增强系统，基于 国际领先的四重差分参数叠加体制和高精度差分参 数播发体制, 实现了覆盖中国及周边地区的分米级 星基增强高精度服务。分米级星基增强服务相比地 基增强服务而言无需在地面建设大量基础设施, 且 高精度服务能力可满足绝大部分经济和社会发展的 需求，是推广高精度服务的重要途径。目前，四大 卫星导航系统均已建成或开展星基增强系统建设, 欧洲正在推进免费的星基增强服务，日本正在推进 厘米级的星基增强服务。此外，商业公司也正在涌 入星基增强服务市场。受服务覆盖区域的限制，目 前 “一带一路” 沿线大部分地区尚未实现星基增强 服务的推广，需加快抢占这一空白市场。

为更好地推进北斗在 “一带一路” 沿线应用落 地, 应加强北斗系统服务建设, 为其提供必要的系 统开放服务平台，让北斗特色服务尽快走出国门， 走进“一带一路”沿线国家。

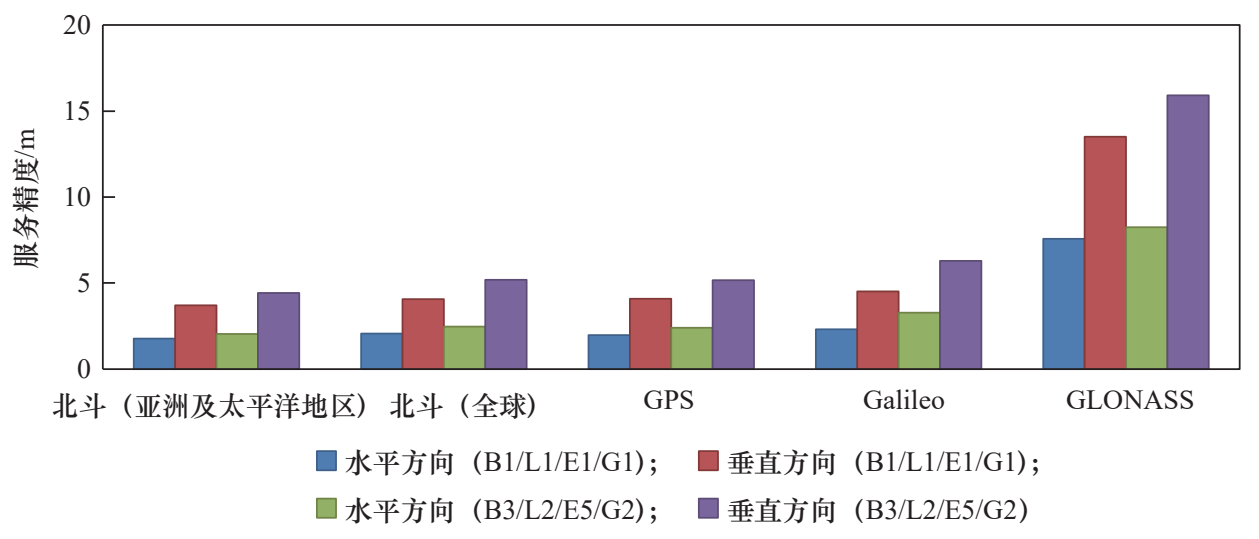

图 2 全球四大卫星导航系统定位服务精度比较 


\section{3. 应用产业层面}

卫星导航系统的影响力主要体现在应用层面。 与国外卫星导航应用的企业相比，国内企业尽管整 体发展迅速，但由于产业发展起步晚，卫星导航产 业链上下游企业普遍规模小、力量分散、竞争力较 弱。根据 2017 年欧盟发布的《GNSS 市场报告》 [6], 中国市场占据全球市场的份额为 $11 \%$ ，相比美国、 欧盟、日本等有明显差距（见图 3)。

以美国为例, GPS 系统与各种增强、辅助手段 和技术的发展，为其卫星导航产业的整体发展提供了 得天独厚的条件，造就了如高通公司、博通公司、天 宝导航公司、苹果公司等全球领先的 GPS 芯片、基 带产品、用户设备和服务提供商, 催生了以 GPS 应 用为核心的卫星导航应用产业，形成了完整的卫星导 航应用产业链, 实力水平居全球领先地位 [7]。美国 在卫星导航应用领域的领先地位表现为技术与产品的 领先性，产品的规模化，完整的卫星导航应用服务体 系以及对全球卫星导航应用领域的强大影响力。

相比而言，国内近几年通过多种形式推广应用北 斗服务和终端产品, 带动了相关产业和企业的快速发 展壮大。但整体而言, 芯片、高端器件和产品仍与国 外有一定差距。北斗应用要在 “一带一路” 推广应用 中实现对 GPS 的 “弯道超车”，在基本服务能力相当 的条件下，基于北斗特色服务提升差异化竞争力、创 造新的市场切入点和增长点是现实选择。

\section{三、北斗 “一带一路” 应用服务性能增强方法}

\section{（一）星基增强}

国外卫星导航系统本身目前只能提供精度最

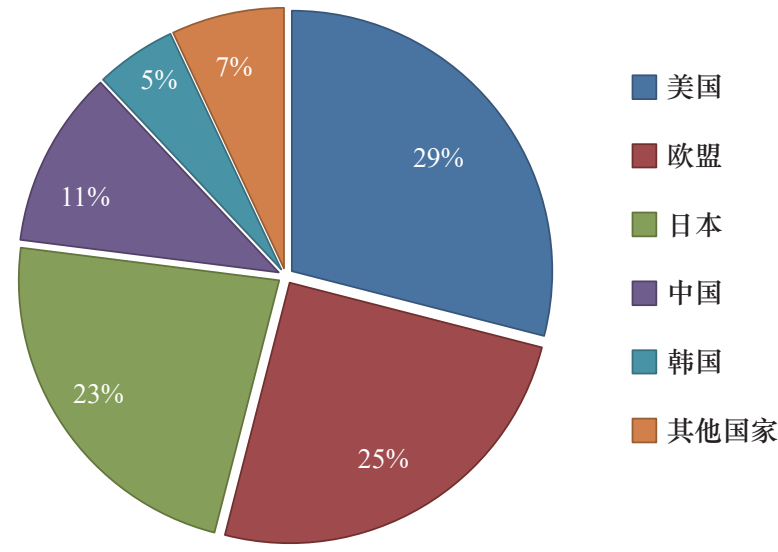

图 3 卫星导航产业市场份额分布
高为米级的定位服务，更高精度的广域定位服 务, 则需要在其基础上另外建立星基增强系统 (SBAS)，例如美国的WAAS、欧洲的地球静止导 航重叠服务（EGNOS）以及俄罗斯卫星导航增强 系统 (SDCM) 等。以上系统级的 GPS/GLONASS 增强系统播发的改正参数包含轨道、卫星钟差改 正数以及完好性参数。

北斗分米级星基增强系统通过首创的四重差分 体制，同步计算基本导航电文参数以及星基增强参 数, 并实现两类参数的一体化、同步播发。如图 4 所示, 北斗四重差分参数在通常的轨道、卫星钟差 改正数的基础上，进一步进行空间环境误差的改正， 叠加了电离层格网改正数以及分区综合改正数。并 利用北斗广播电文协议的空余字段进行参数增量式 编排，通过地球同步轨道（GEO）卫星向所有用户 进行播发。

地面基础设施需要进行重点建设。北斗在 “一 带一路” 沿线仅能实现 3 5 m 的定位精度。为了实 现分米级定位服务覆盖，需在 “一带一路” 国家和 地区建设少量地面监测站。根据当前分米级服务系 统的服务能力, 每个地面监测站可实现覆盖半径约 $1000 \mathrm{~km}$ 区域的分米级星基增强服务。

北斗分米级星基增强系统使北斗成为第一个融 合基本导航、广域增强以及精密定位三类服务模式 为一体的卫星导航系统, 具备了优于 GPS 的系统 级星基服务性能, 成为北斗差异化服务能力提升的 有效途径。

目前，北斗基本导航的系统空间信号精度达到 了 $0.8 \mathrm{~m}$, 广域增强为 $0.3 \mathrm{~m}$, 精密定位为 $0.2 \mathrm{~m}$ 。 其中，分米级星基增强覆盖区域如图 5 所示。从 图 5 中可以看到, 北斗系统的分米级服务覆盖的浅 紫色区域主要集中在中国及周边区域。

在 “一带一路” 推广应用中，通过扩展地面观 测网络以及卫星播发资源, 能够将北斗高精度星基

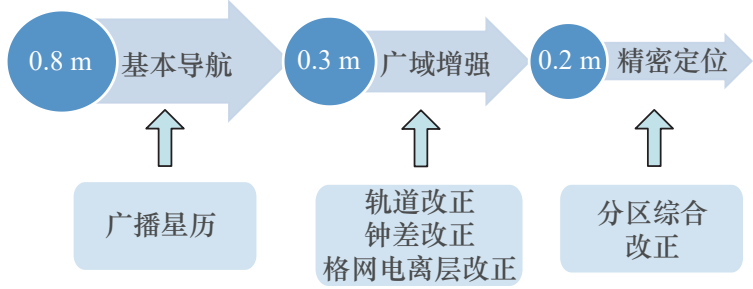

图 4 北斗系统分米级星基增强服务当前覆盖范围 
增强服务推广至 “一带一路” 所涉及的国家和地区。

根据当前北斗分米级服务系统的设计原则, 基于每个地面监测站的观测数据可实现半径约 $1000 \mathrm{~km}$ 区域内的分米级星基增强服务。基于 “一 带一路” 沿线的观测情况新增建设约 18 个连续观 测台站，如图 6 所示，图 6 中的浅紫色区域为基于 现有和新增连续台站数据的北斗分米级服务覆盖区 域。表 1 统计了 “一带一路” 北斗分米级星基增强 覆盖区域的位置服务性能。通过在该区域新建少量
北斗连续观测台站，能够实现用户三维位置精度 优于 $0.25 \mathrm{~m}$ 的服务性能。此外, 将北斗与其他导 航系统进行融合能进一步提高服务的性能及服务 可用性。

北斗四重差分参数是通过分布于赤道上的 5 颗 GEO 卫星向用户进行广播。在 “一带一路” 欧 洲地区存在 GEO 无法全覆盖的情况。为实现该区 域分米级星基增强服务的可用性，考虑利用北斗 系统备份或者退役 GEO 卫星进行补充。依据现有

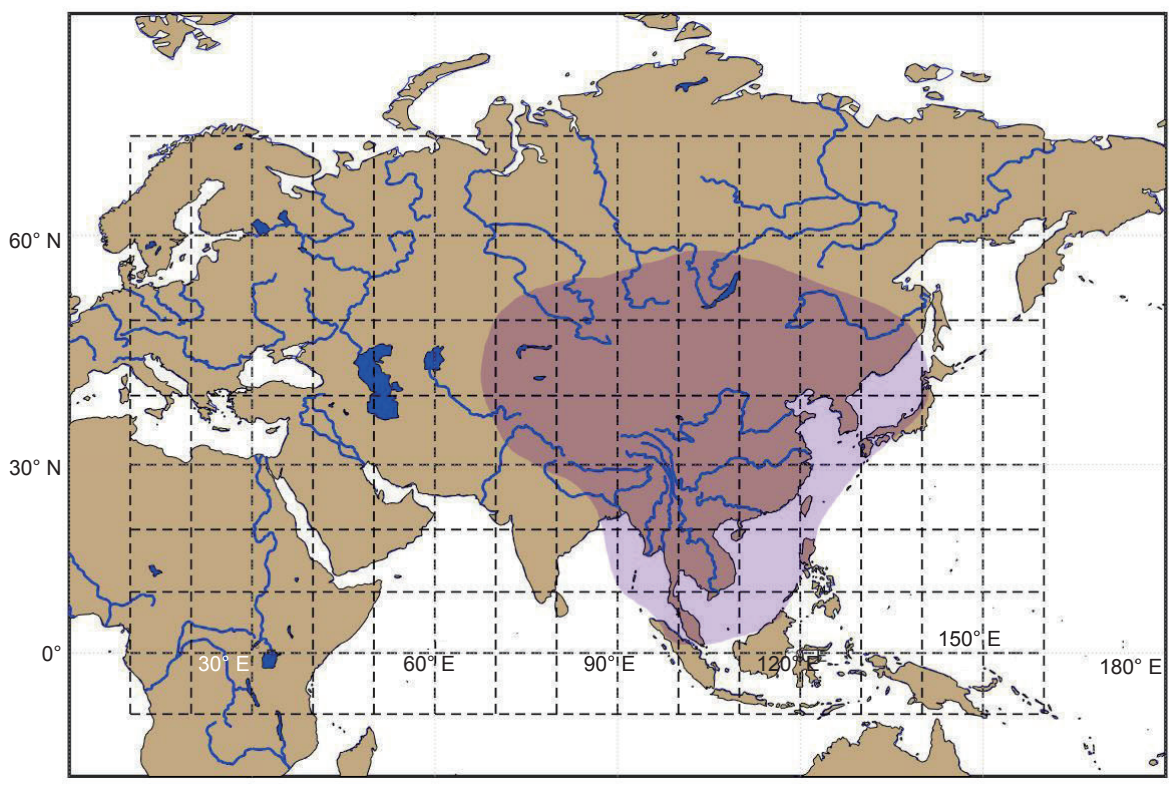

图 5 北斗系统分米级星基增强服务当前的覆盖范围

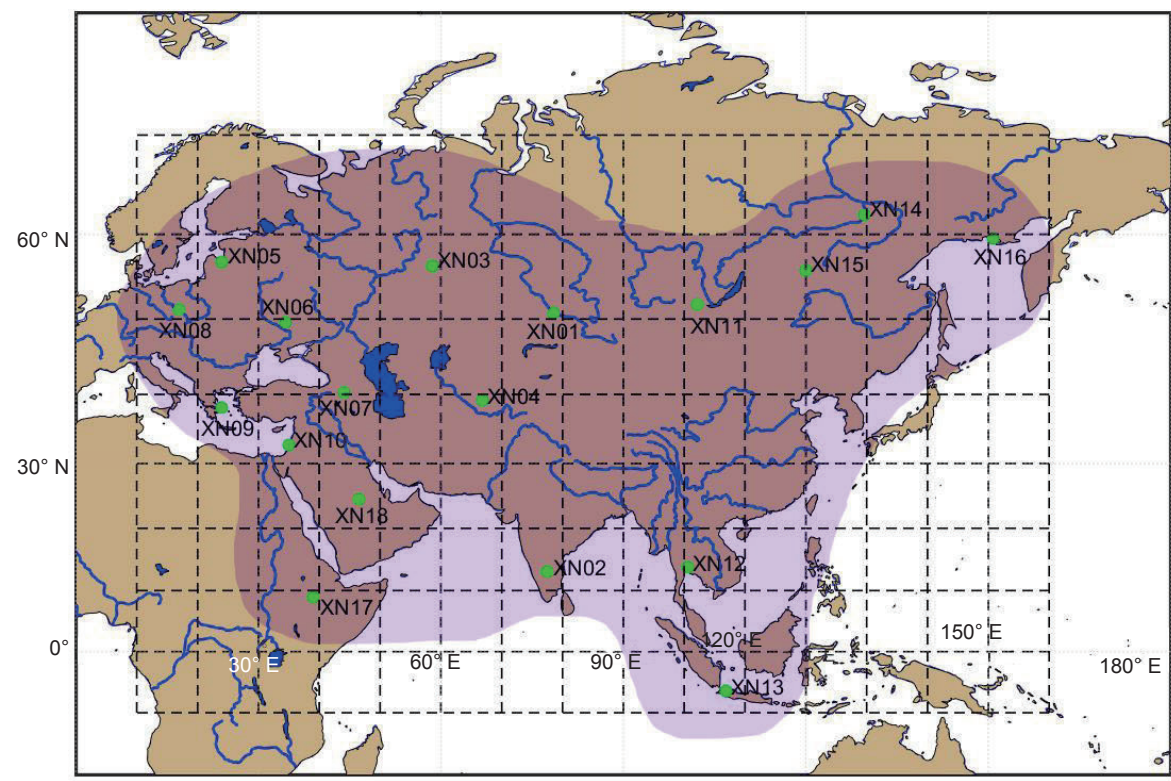

图 6 “一带一路” 分米级星基增强监测站分布及覆盖情况 
电文协议和现有的服务频段, 向目前难以覆盖区域 播发星基增强电文信息。

\section{（二）北斗短报文海外服务系统}

向 “一带一路” 国家和地区推广普及短报文服 务, 需进行北斗系统海外服务能力扩展, 搭建服务 海外的专用系统平台。

\section{1. 北斗短报文海外服务系统}

向 “一带一路” 沿线国家提供大众化的服务, 可设计一套服务海外的军民融合信号，扩建新体制 信号的运行与处理中心及海外运营系统与服务平 台, 提升北斗海外服务应用能力。根据海外应用规 模, 可释放出每小时数千万次的服务能力资源, 开 发应用芯片, 大幅降低终端成本、功率等, 有效嵌 入个人智能终端。

\section{2. 卫星系统}

根据短报文海外服务容量的需要, 前期可基于 现有的 GEO 卫星提供服务。当现有的 GEO 卫星 难以满足未来大规模分米级用户服务需求时, 考虑 针对 “一带一路”服务区域增发增强型 GEO 卫星。 卫星的初步定点经度设计在东经 $60^{\circ}$ 或 $140^{\circ}$ 区域, 星上搭载短报文和卫星无线电导航业务 (RNSS) 载荷, 既能增强现有服务区域, 还可以扩展 “一带 一路” 沿线的服务区域。届时，补充服务的卫星将 同步提供海外短报文和分米级星基增强服务系统性 能, 进一步提升北斗系统服务的竞争力。

\section{（三）示范应用}

自北斗的短报文和星基增强服务开通以来，为 更好推动系统的应用推广, 先后制定了用户接口协

表 1 “一带一路” 各区域分米级精度试验结果

\begin{tabular}{lc||lc}
\hline 分区编号 & 三维定位误差 $/ \mathrm{m}$ & 分区编号 & 三维定位误差 $/ \mathrm{m}$ \\
\hline XN01 & 0.21 & XN10 & 0.12 \\
XN02 & 0.19 & XN11 & 0.10 \\
XN03 & 0.13 & XN12 & 0.18 \\
XN04 & 0.15 & XN13 & 0.17 \\
XN05 & 0.15 & XN14 & 0.12 \\
XN06 & 0.14 & XN15 & 0.14 \\
XN07 & 0.09 & XN16 & 0.22 \\
XN08 & 0.15 & XN17 & 0.20 \\
XN09 & 0.16 & XN18 & 0.19 \\
\hline
\end{tabular}

议、用户应用算法等系列标准文件。芯片、板卡、 终端生产厂家也已完成了相应的协议升级和应用软 件改造。面向 “一带一路” 应用, 需要完善相关知 识产权布局, 升级现有协议、标准, 满足更多用户、 更广区域、更高精度的服务要求。

在芯片领域, 重点突破多模兼容 (SoC) 导航 芯片的系列关键技术, 发展具有自主知识产权的多 系统融合导航定位芯片, 对标国际主流芯片, 进一 步提升产品竞争力。在用户终端领域, 加强北斗短 报文、星基增强等特色技术的融合应用，设计标准 化、易移植的嵌入式软件, 开发多型谱、通用型的 用户终端, 包括北斗单频、增强型单频、双频导航、 多频精密单点定位终端, 实现从芯片到终端的便捷 应用, 重点发展面向智能应用的高精度终端产品。 在 “一带一路” 沿线地区推广方面, 采用因地制宜 的策略, 在深入调研本地化需求的基础上, 做好针 对性的卫星无线电测定业务（RDSS）特色服务产 品以及高精度导航产品研发, 提供适销对路的产品 和服务。

\section{四、保障建议}

一是加快北斗特色服务开放进程。尽快开展分 米级星基增强和短报文特色服务面向 “一带一路” 沿线国家的应用推广。

二是合力推进海外基础设施建设。通过多种渠 道, 以多种形式的国际合作推广北斗海外应用, 促 进海外基础设施落地。

三是积极探索特色服务示范体系。研发针对 “一带一路”重点地区的示范性产品; 依托国内具 有丰富海外工程经验的企业, 采用 “借船出海” 的形式搭建交通位置、智慧城市等北斗特色服务 示范应用的推广平台。

\section{参考文献}

[1] Fairhurst P. Commentary: High-precision positioning is going mainstream [J]. GPS World, 2019 (1): 35-37.

[2] 杨元喜. 综合 PNT 体系及其关键技术 [J]. 测绘学报, 2016, 45(5): 505-510.

Yang Y X. Concepts of comprehensive PNT and related key technologies [J]. Acta Geodaetica et Cartographica Sinica, 2016, 45(5): 505-510.

[3] 杨元喜. 弹性PNT 基本框架 [J]. 测绘学报, 2018, 47(7): 893-898. Yang Y X. Resilient PNT concept frame [J]. Acta Geodaetica et 
Cartographica Sinica, 2018, 47(7): 893-898.

[4] Wang L, Chen R Z, Li D, et al. Initial assessment of the LEO based navigation signal augmentation system from Luojia-1A satellite [J]. Sensors, 2018, 18(11): 3919.

[5] 中国卫星导航系统管理办公室测试评估研究中心. GNSS 服务 监测评估月报2018年第12期 [R]. 北京: 中国卫星导航系统管理 办公室测试评估研究中心, 2018 .

China Satellite Navigation System Office Test Assesment and Research Center. GNSS service monitoring and assesment month report (2018, No.12) [R]. Beijing: China Satellite Navigation Sys- tem Office Test Assesment and Research Center, 2018.

[6] GSA. 2017 GNSS market report [R]. Prague: Carlo des Dorides, 2017.

[7] 北京空间科技信息研究所. 世界航天发展年度报告卫星导航分 册 (2017) [R]. 北京：北京空间科技信息研究所, 2017.

Beijing Space Technology and Information Research Center. The annual report of world space development: Satellite navigation part (2017) [R]. Beijing: Beijing Space Technology and Information Research Center, 2017. 